\title{
Diversity and potentiality of multi-criteria decision analysis methods for agri-food research
}

\author{
Geneviève Gésan-Guiziou ${ }^{1}$ (D) A Aude Alaphilippe ${ }^{2} \cdot$ Joël Aubin $^{3} \cdot$ Christian Bockstaller $^{4} \cdot$ Rachel Boutrou $^{1}$. \\ Patrice Buche ${ }^{5}$. Catherine Collet $^{6}$. Agnès Girard ${ }^{7}$. Vincent Martinet ${ }^{8} \cdot$ Jeanne-Marie Membré $^{9} \cdot$ Régis Sabbadin $^{10}$. \\ Marie Thiollet-Scholtus ${ }^{4} \cdot$ Hayo M.G. van der Werf ${ }^{3}$
}

Accepted: 23 October 2020 / Published online: 16 November 2020

(C) INRAE and Springer-Verlag France SAS, part of Springer Nature 2020

\begin{abstract}
There is a growing demand for moving towards sustainable agri-food systems which per nature covers a complex network of activities and domains; such systems will benefit from multi-criteria decision analysis (MCDA) methods. Although some reviews on MCDA in agri-food research have been published, none of them covered the whole value chain. In this article, a corpus of 954 articles published by INRA scientists from 2007 to 2017 was used to study the diversity and potentiality of MCDA techniques. For the first time, experts from more than 10 agri-food domains worked altogether to annotate the articles, carry out a multivariate analysis, and finally interpret the statistical results to identify the specificities of certain domains and the complementarities between domains and to suggest avenues for future agri-food research. One-third of the studies were based only on a list of indicators, even when their purpose was to choose, sort, or rank options. Regardless of the scientific discipline in the agri-food sector, MCDA studies rarely considered temporal dynamics, spatial scale changes, or stakeholder contributions. As the agri-food system becomes increasingly sustainable in the near future, the use of MCDA methods will accelerate. To become more effective, they will have to include ecosystem services, even outside the scope of ecological studies. Similarly, MCDA studies will need to include participatory science to involve stakeholders (i.e., public authorities, governmental agencies) and end-users (i.e., farmers, producers, industrials, consumers) in the construction of the multi-criteria evaluation but also in the resulting decisions.
\end{abstract}

Keywords Sustainability $\cdot$ Agriculture $\cdot$ Agro-industry $\cdot$ Design $\cdot$ Choice $\cdot$ Environment $\cdot$ Indicators $\cdot$ INRAE

Geneviève Gésan-Guiziou

genevieve.gesan-guiziou@inrae.fr

STLO, INRAE, Institut Agro, F-35042 Rennes, France

2 INRAE, UERI-Gotheron, F-26320 Saint-Marcel-lès-Valence, France

3 SAS, INRAE, Institut Agro, F-35042 Rennes, France

4 Université de Lorraine, INRAE, LAE, F-68000 Colmar, France

5 University of Montpellier, INRAE, IATE, F-34060 Montpellier, France

6 University of Lorraine, AgroParisTech, INRAE, Silva, F-54000 Nancy, France

7 INRAE, LPGP, F-35000 Rennes, France

8 University Paris-Saclay, INRAE, AgroParisTech, Economie Publique, F-78850 Thiverval-Grignon, France

9 INRAE, Oniris, Secalim, F-44307 Nantes, France

10 INRAE, MIA, F-31320 Castanet Tolosan, France

\section{Introduction}

Over the last decade, a growing agreement has emerged on the need to address sustainability of agri- food systems (Eakin et al. 2017). Agri-food systems cover the whole value chain and encompass networks of actors and activities from production to waste disposal as well as resource flows and outcomes (Meynard et al. 2017). As widely recognized, agri-food systems face multiple challenges such as food insecurity, environmental degradation, and chronic poverty in context of climate change and economic instability (Godfray et al. 2010), so that any quest of sustainability requires an integration of social, environmental, and technological processes. These considerations led Eakin et al. (2017) to define an agri-food system as sustainable if it achieves or maintains food security while meeting social demand of cultural value and decision autonomy and respecting the integrity of the social-ecological processes driving the provision of current and next generations with food. Thus, any assessment of agri-food system 
sustainability considered as an important support for implementation of sustainable agri-food systems (Pope et al. 2004) requires a multi-criteria approach founded on multidisciplinary effort. Multi-criteria decision analysis (MCDA) methods exist and are often used in sustainability science, but they require far more use and application in agri-food system decision-making than they currently receive (Eakin et al. 2017).

According to Belton and Stewart (2002), MCDA is "an umbrella term to describe a collection of formal approaches which seek to take explicit account of multiple criteria in helping individuals or groups explore decisions that matter." This definition clearly indicates that a broad variety of approaches exist "under the umbrella." They can be divided into two parallel, but not entirely disconnected, scientific branches. The operational research, which emerged in the 1940s, has led to a variety of methods to support decision-making, such as Multi-attribute Utility Theory (MAUT) and Analytic Hierarchy Process (AHP) approaches from the American school, as well as outranking methods such as ELimination Et Choice Translating Reality (ELECTRE) and Preference Ranking Organization METHod for Enrichment of Evaluations (PROMETHEE) from European schools (Herva and Roca 2013). In parallel, the emergence of the issue of sustainability due to increasing concern for the environment has led to an "explosion" of initiatives that develop assessment methods often based on sets of indicators (Singh et al. 2012). MCDA methods have been applied widely, leading to reviews or meta-analyses in sectors such as medical health (Mardani et al. 2019) or civil engineering, construction, and building technology (Zavadskas et al. 2018). For agri-food systems, reviews were published, but they cover only some restricted areas of agri-food system, for instance, Sadok et al. (2008) focused on cropping systems, Madoumier et al. (2019) on food processes, Vergara-Solana et al. (2019) on the aquaculture industry, or Fagioli et al. (2017) on the multifunctionnality of olive oil value chain.

The objective of the present study was to emphasize the diversity and potentiality of MCDA methods for agri-food research (Fig. 1). To do so, for the first time, a group of scientists with expertise covering the whole agri-food system worked altogether to annotate a substantial amount of articles and further interpret the results of a multivariate analysis to deduce what has been done and what is still missing in agri-food research. The group of experts reviewed a unique set of 954 MCDA studies by researchers from INRA (the French National Institute for Agricultural Research) of environmental science, plant and animal sciences, process engineering, food security, and social sciences.

\section{Materials and methods}

\subsection{Selection and annotation of scientific articles}

The articles were selected and annotated in the framework of an INRA internal project, run in 2016-2019, gathering experts covering the diversity of the disciplinary approaches and applications developed in the institute (agronomy, animal science, biological science, genetics, silviculture, environmental science, process engineering, food technology, food safety, nutrition, consumer science, risk-benefit assessment, economics, applied mathematics, applied statistics, artificial intelligence). The selection and annotation of papers were described in the related data paper (Gésan-Guiziou et al. 2019).

Relevant articles published by INRA researchers from 2007 to mid-2017 were extracted in mid-2017 from the Web of Science using two queries as described in Gésan-Guiziou et al. (2019).

The resulting corpus of articles (4920) was then manually classified as MCDA (954) or non-MCDA (3966) by domain experts using a set of positive and negative criteria that defined an "MCDA article." In order to achieve this task, these data (4920 papers) have been split into 13 Excel files corresponding to scientific domains to cover the diversity of the disciplinary approaches and applications developed in INRA (see Gésan-Guiziou et al. 2019). Classification has been done in two steps. First, experts were trained to annotate the articles through a double-blind annotation that has been done on at least 50 randomly drawn articles in each of the 13 scientific domains. The annotation consensus ranged from 70 to $92 \%$ according to the scientific domain. This first annotation step also allowed defining the classification rules (MCDA or nonMCDA criteria). The remaining set of articles has been annotated by at least one annotator. To be classified as MCDA papers, articles had to present either (i) a study of several alternatives based on several criteria/indicators with interpretation (prioritization, ranking, comparisons,), even if done criterion by criterion, or (ii) a study based on the design of aggregated indicators representing a non-measurable phenomenon/concept, or (iii) a multi-objective or single-objective optimization study with constraints expressed on criteria, or (iv) a study on methodologies/methods explicitly related to a MCDA approach, or (v) strategic/opinion paper about MCDA approaches or issues requiring MCDA methods, or (vi) a study which identifies a list of criteria to be considered in assessing a system/property/concept. On the other hand, the papers were classified as non-MCDA if they presented (i) a descriptive study based on a set of variables/indicators not interpreted in terms of comparison of alternative scenarios, or (ii) the design of a phenomena predictive model (statistical, numerical, etc.) unless it was explicitly integrated in a broader approach of multi-criteria assessment, or (iii) a monoobjective optimization study without constraints.

Next, the same group of INRA experts classified the MCDA articles according to eight criteria: type of MCDA study, purpose of the MCDA, target audience, dimensions assessed, system/object assessed, spatial scale assessed, temporal scale assessed, and stakeholder contributions. The choice of those criteria was inspired from preliminary choices 
Fig. 1 Illustration of the networks of activities of the food value chain, from production to waste disposal, covered by agri-food system

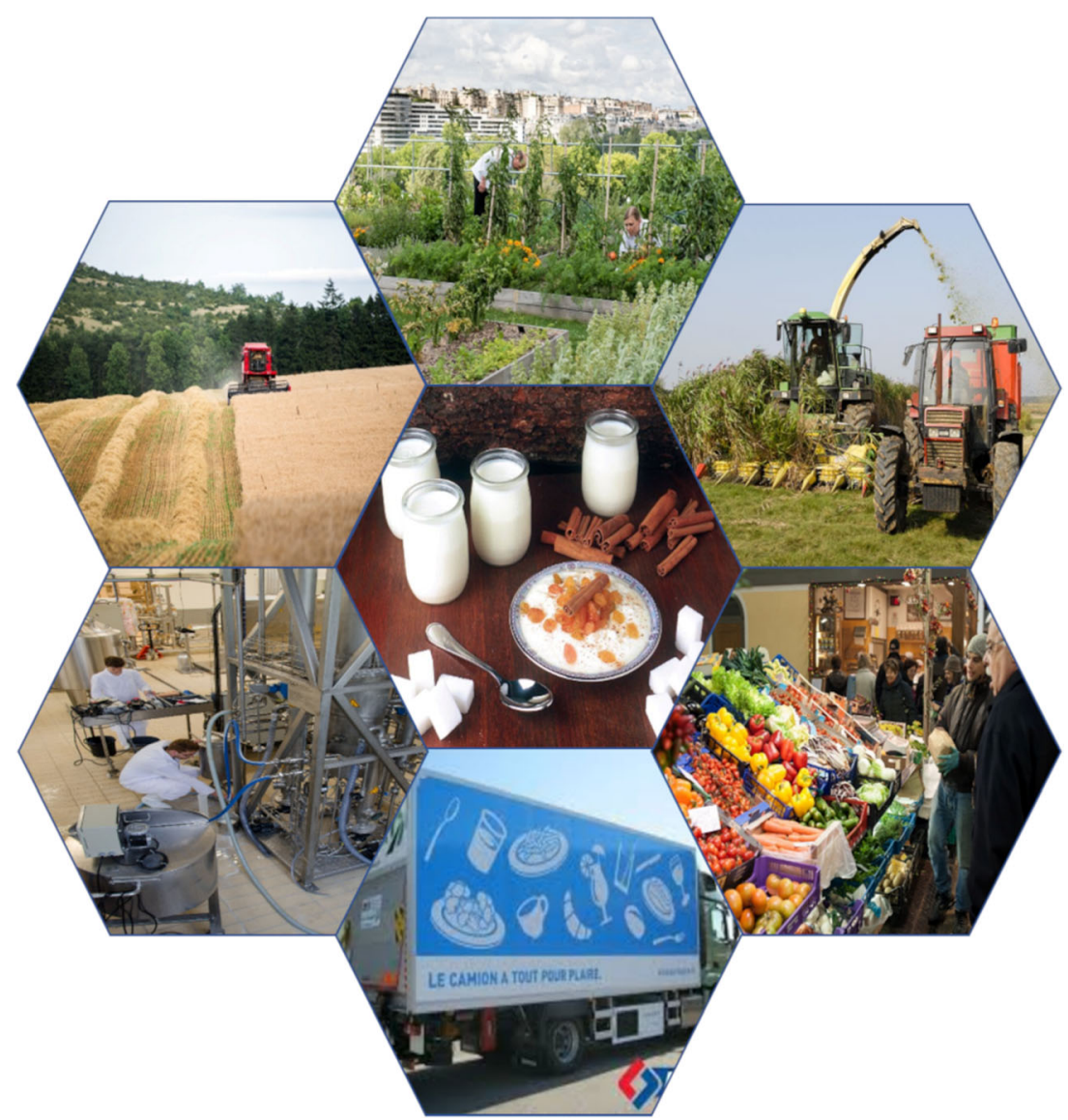

in a methodological pathway to assess sustainability (Lairez et al. 2017), such as the purpose ("why?"), audience ("for whom?"), dimension and system/object assessed" (“what?"), spatial scale ("where?"), and temporal scale ("when?").

Categories associated with each of those 8 criteria, listed in Gésan-Guiziou et al. (2019), were used to annotate the 954 MCDA articles. The Excel files with the annotations and classifications are available in a public repository presented by Gésan-Guiziou et al. (2019).

Finally, the resulting dataset was analyzed by multivariate technique as described below.

\subsection{Statistical analysis}

Each of the eight criteria had 5-10 binary subcriteria, yielding a total of 58 binary variables. These subcriteria were used to characterize each article. In other words, the dataset consisted of a cloud of 954 points in 58-dimensional space. Multiple Correspondence Analysis of the dataset was performed to analyze the structure of the cloud and extract clusters of similar subsets of articles. The R package FactomineR was used (http://factominer. free.fr/index.htm) (Le et al. 2008). The first step consisted of calculating the number of articles with each sub-criterion. Then, Multiple Correspondence Analysis (FactomineR function $\mathrm{mca}$ ) was used to project the dataset onto the subspace spanned by the two dimensions/axes (i.e., vectors) that explained the most variability in the cloud. In Multiple Correspondence Analysis, the inertia of axes (interpreted as percentage of explained variability), used to rank axes, is small by construction. In fact, the percentage for any axis is upper-bounded by $\mathrm{J} /(\mathrm{K}-\mathrm{J})$, where $\mathrm{J}$ is the number of variables ( 8 in our case) and $\mathrm{K}$ is the number of modalities (58 in our case). Therefore, by construction, no axis can "explain" more than $8 / 50<16 \%$ of the variability.

In this study, the first two dimensions, and even the third one, were able to distinguish articles based on some of their characteristics (FactomineR function dimanalysis). Hierarchical clustering on Principal Components (Factomine R function $H C P C$ ) was then applied to the resulting cloud to group individuals into an optimal number of clusters (determined from the inflection point of the inertia gain), which was four. In each cluster, five "paragons" (i.e., individuals closest to the center of the cluster) were identified and used to illustrate the cluster.

\section{Results and discussion}

This study characterized the diversity of situations in which MCDA methods were applied in the agri-food sector and analyzed the type of MCDA approaches used to date as well as 
their potentiality in accompanying the transition of agri-food systems towards greater sustainability.

The results obtained in this study may have been influenced by sampling studies from only one research institute, INRA, which raises questions about the representativeness of the sample. Ideally, the study would be repeated for a broader sample of articles. However, one can assume that due to the large number of INRA employees ( $>8500$ ), the diversity of research conducted within the institute and its high ranking (number one agricultural research institute in Europe and number two in the world by number of peer-reviewed articles published per year), the articles covered a broad range of the agri-food research performed in the rest of the world.

\subsection{Diversity of MCDA studies in the agri-food research}

\subsubsection{Through the analysis of the entire dataset}

The number of MCDA articles published per year by INRA researchers increased continuously from 56 in 2007 to 144 in 2016 . The analysis of the dataset showed that the largest group of articles, that represented a third of the MCDA articles analyzed (328 out of 954), used a list of criteria or indicators (i.e., a non-dedicated method) instead of a dedicated method to rank, classify, or compare options, even criterion by criterion ("type of MCDA study," Fig. 2a). The second largest group of articles (279) applied a dedicated MCDA method, such as life cycle assessment (LCA), to case studies without developing the method further. Smaller groups of articles reported several developments in MCDA methods, including the following:

- Development of dedicated MCDA methods (163), each with a given set of criteria and a framework to organize and aggregate them. One example is the Multi-attribute Assessment of the Sustainability of Cropping systems (MASC) method (Sadok et al. 2009).

- Investigation of specific methodological issues associated with MCDA methods (141) (e.g., scale change, functional units, uncertainty management). Examples include sensitivity analysis of a DEXi-based decision tree (Carpani et al. 2012), spatialized application of LCA (Nitschelm et al. 2016), and scientific data reliability assessment (Destercke et al. 2013).

- Development of generic methods (48), which do not have a given set of criteria but can define, choose, organize, or aggregate criteria. One example is the development of a generic flexible multi-criteria querying method (Destercke et al. 2011) that enables specific decision support systems to be designed, such as the one designed to select food packaging (Guillard et al. 2015).
This analysis revealed two main research purposes: to create new knowledge (68\%) (e.g., identify changes in state, compare systems) and to choose, sort, or rank options (56\%) (Fig. 2b). As expected, given publication in a peer-reviewed article, the audience was mainly scientists (92\%), development engineers $(61 \%)$ (e.g., from technical institutes, consulting firms, and chambers of agriculture), and to a lesser extent public stakeholders (28\%) (e.g., national and local governments; the European Union; water, environmental, and health and safety agencies) (Fig. 2c). The main dimensions assessed were functional and technical performances, followed by environmental impacts, product quality, economic aspects, and much less often, despite their importance to sustainability, social and health impacts (Fig. 2d). Unsurprisingly for the agri-food sector, more than half the objects studied were animals, plants, next food, and processing (Fig. 2e). Most studies focused on individuals (e.g., plants, animals), groups of individuals, or small systems (e.g., farms, diets, forests), while few studies considered large-scale aspects (Fig. 2f). The same was true for the temporal scale, since most studies assessed a system or production cycle at a single point in time (Fig. 2g). Studies of temporal dynamics (for instance, on resilience or robustness) or long-term trends were rare. Finally, studies considered that stakeholder contributions were rare, since stakeholders either did not participate or were not specified in most studies (Fig. 2h). Undoubtedly, to move towards sustainable agri-food systems, large-scale studies, studies considering temporal dynamics, as well as studies involving multiactor and citizen engagement are needed.

\subsubsection{Through statistical clustering}

The Multiple Correspondence Analysis of the dataset made it possible to split the 954 articles into clusters representative of the main categories of multi-criteria studies at INRA and then revealing typical MCDA approaches and methods used in agri-food research. For that purpose, the inertia of axes (interpreted as percentage of explained variability) was determined as $8.68 \%$ and $5.33 \%$. These values were low, as explained in the Material and Methods section, but quite usual in the literature for Multiple Correspondence Analysis, for instance, $10.72 \%$ and $8.66 \%$ in Ayele et al. (2014). These two dimensions were used to distinguish articles based on some of their characteristics and split the 954 articles hierarchically into four clusters of $239,280,359$, and 76 articles, respectively. Each of these clusters is illustrated using one of its five paragons.

Cluster 1 (239 articles) grouped a quarter of the articles that were from novice MCDA users. It included more than 120 articles on the genetic performance, health, and welfare of individual animals that targeted an audience of animal scientists. These studies identified elements of an option to improve, create knowledge, or choose, sort, or rank options. 
Fig. 2 Diversity of the MCDA studies in agri-food research shown through the classification of the 954 annotated articles. The eight criteria of classification are (Gésan-Guiziou et al. 2019): (a) type of MCDA study, (b) purpose of MCDA study, (c) target audience, (d) dimension assessed, (e) system/object assessed, (f) spatial scale assessed, (g) temporal scale assessed, and (h) stakeholder contributions. Numbers indicated the number of articles classified in each subcriteria a. Type of study

Development of generic MCDA methods

Other

Specific methodological issue

Characteristics of MCDA methods

Use of dedicated MCDA method

Use of non-dedicated method

\section{b. Purpose}

To access a new market To promote new knowledge To report To organize actions

To assess the strengths and weaknesses of different options

To choose, sort or rank options To create new knowledge

\section{(a)}

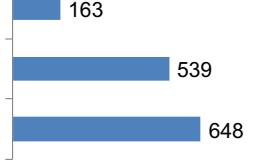

C. Audience

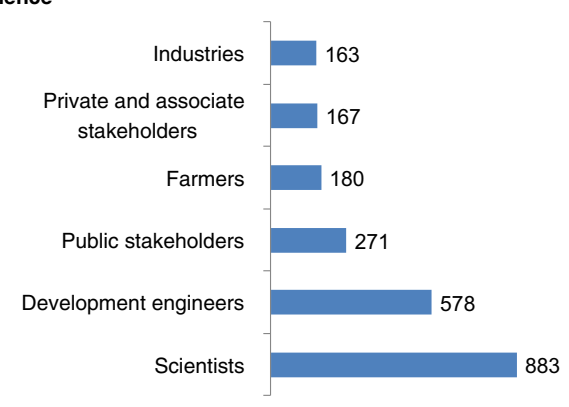

d. Dimension assessed

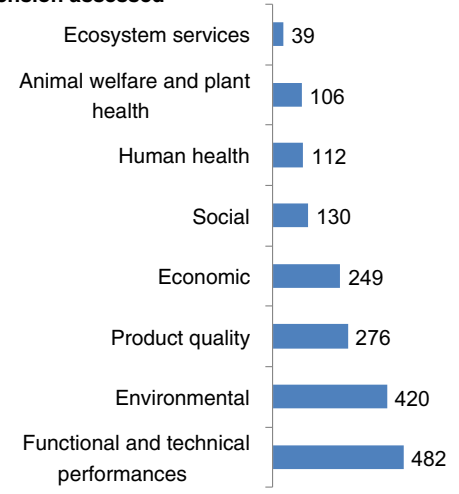

e. System/object assessed

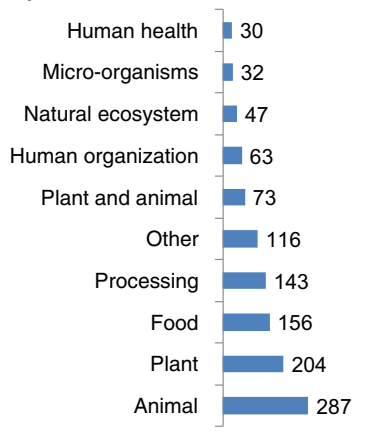

f. Spatial scale
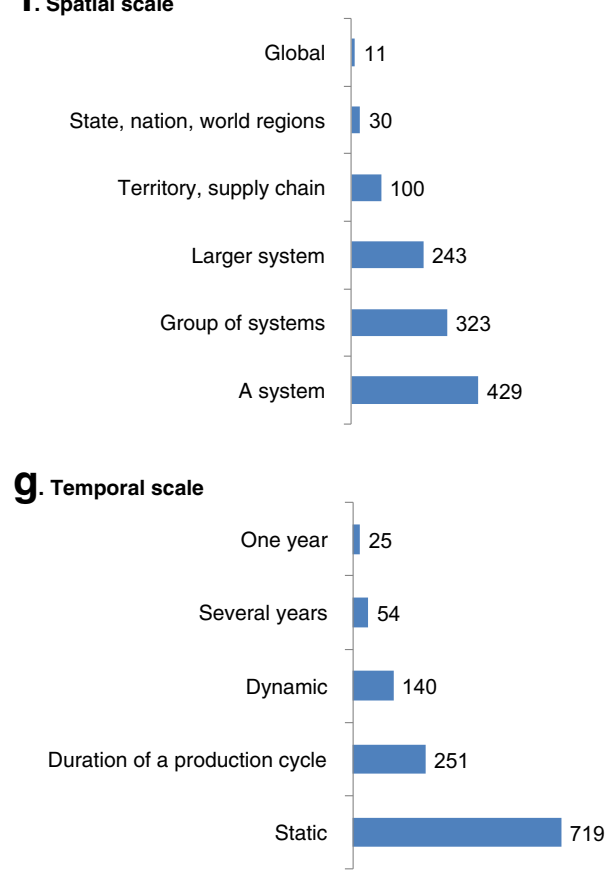

h. Stakeholder contributions

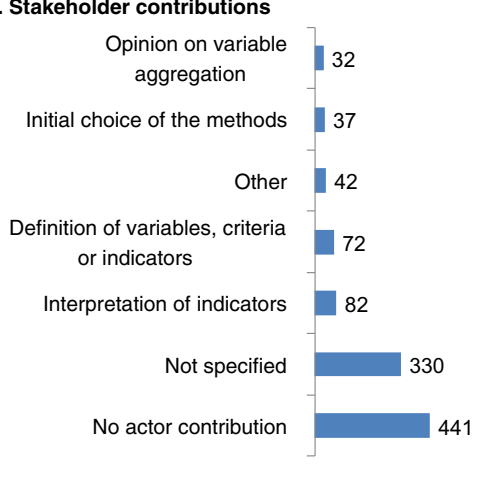

This cluster included studies that were relatively frequent in the broader field of multi-criteria assessment (with or without calculations) but that did not have "MCDA" in the title or abstract. These studies assessed options according to several criteria but did not explicitly mention MCDA as a technique or a scientific approach. In this sense, their authors were novice MCDA users who did not consider temporal dynamics or dynamic sustainability aspects (e.g., resilience, robustness, vulnerability) and did not involve stakeholders. Cluster 1 is illustrated with a paragon focused on an animal genetic selection method (Shumbusho et al. 2016) that was developed by combining economic indicators (e.g., annual monetary genetic 
gains, economic returns, contribution margins) but without following a specific MCDA method (Fig. 3).

Cluster 2 grouped $30 \%$ (280) of the articles that dealt with food and used a dedicated MCDA method. It consisted mainly of studies of product quality and human health effects of individual foods and their processing that targeted an audience of food and process engineers and scientists. These studies choose, sorted, or ranked options or created knowledge. As in cluster 1 , articles in cluster 2 described studies that tended to ignore temporal dynamics and did not involve stakeholders. Unlike cluster 1, authors used dedicated MCDA methods, particularly multi-objective optimization, to address multiresponse issues. Accordingly, the five paragons identified for this cluster focused on food products. Cluster 2 is illustrated with a paragon that focused on the importance of the functional unit chosen to determine sustainable foods (Masset et al. 2015) (Fig. 4). The objective of the study was to determine the most sustainable foods in the French diet. The authors used a simple aggregation method to calculate a single score from 0 to 3 from the three indicators to identify sustainable foods (score $=3$ ). The study, which targeted researchers, showed that the choice of functional unit is crucial since it can determine which foods are considered sustainable.

Nearly $40 \%$ (359) of the annotated articles were in cluster 3 , which grouped studies of a variety of objects (e.g., territories, plants, animals) analyzed with a dedicated MCDA method. Cluster 3 included articles covered environmental, economic, and social dimensions, as well as ecosystem services, of human organizations or plant- and animal-based systems. It included several disciplines, such as sustainability and environmental science). The studies targeted scientists, engineers, and public, private, and non-governmental stakeholders at the scale of a territory, product chain, or population. The studies chose, sorted, or ranked options; created or provided knowledge; or organized actions. They tended to ignore temporal dynamics, use a dedicated MCDA method, and not involve stakeholders. The five paragons associated with cluster 3 reflected the diversity of objects studied: biomass conversion, biofuels, soil erosion, invasive species, and cropping systems. Several of the studies used LCA, such as BellonMaurel et al. (2013), who focused on scientific issues to consider when applying LCA to the use of waste and biomass. They described current attempts to address these issues and identified the main scientific issues involved in each phase of the LCA framework (Fig. 5).

Articles of these three clusters did not involve stakeholders in the studies, although public and private stakeholders were listed as target audience for almost half of the articles of these three clusters.

Indeed, the few studies (less than 10\%) involving stakeholders were grouped in cluster 4 (76 articles). More precisely, cluster 4 included studies which involved stakeholders in the choice of the method, definition of criteria and indicators, and aggregation and interpretation of indicator results. These studies focused on environmental, social, economic, and productquality dimensions of plant-based, plant-and-animal-based, and food systems. They targeted scientists, engineers, and public and non-governmental stakeholders and focused on individuals or groups of individuals. These studies chose, sorted, or ranked options; created knowledge; or organized actions. They tended to ignore temporal dynamics and use a dedicated MCDA method. Like for cluster 3, paragons of cluster 4 addressed a variety of objects, such as human microbiota, insects, crop diversity, and cropping systems.
Fig. 3 Illustration representative of studies in cluster 1: procedures to compare the cost, monetary genetic gain, and economic efficiency of classic selection and genetic selection plans in the sheep meat industry. Adapted from Shumbusho et al. (2016)

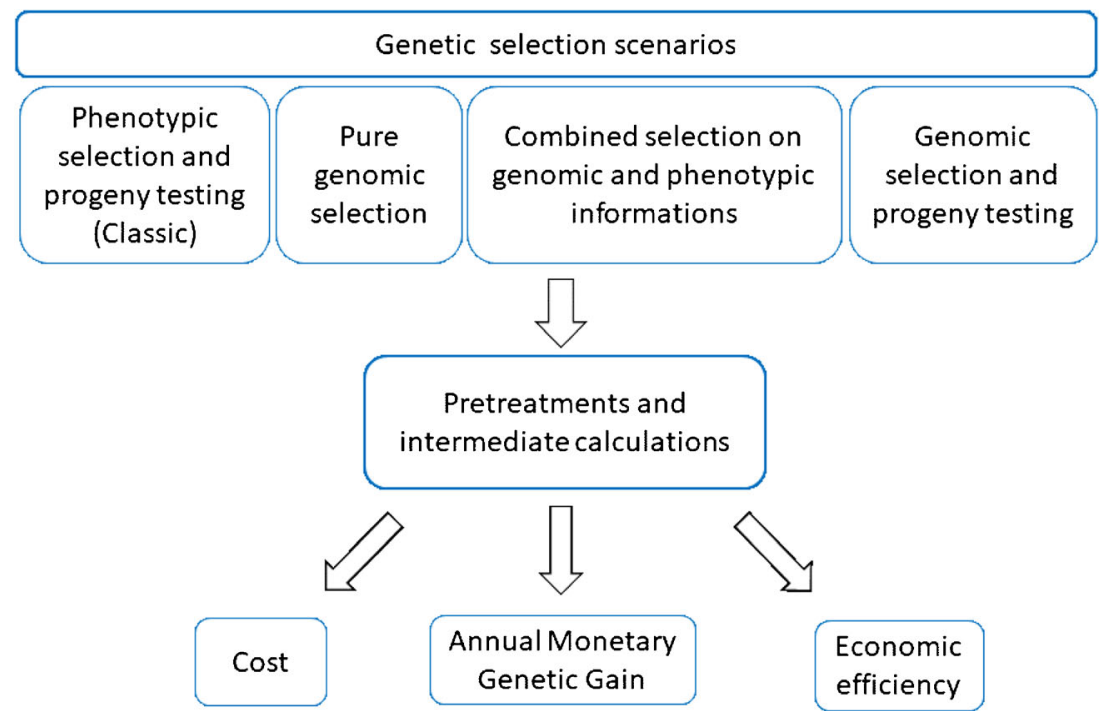

Discussion and conclusions made per criteria (cost, monetary genetic gain and economic efficiency), without mentioning a multicriteria technique or decision 


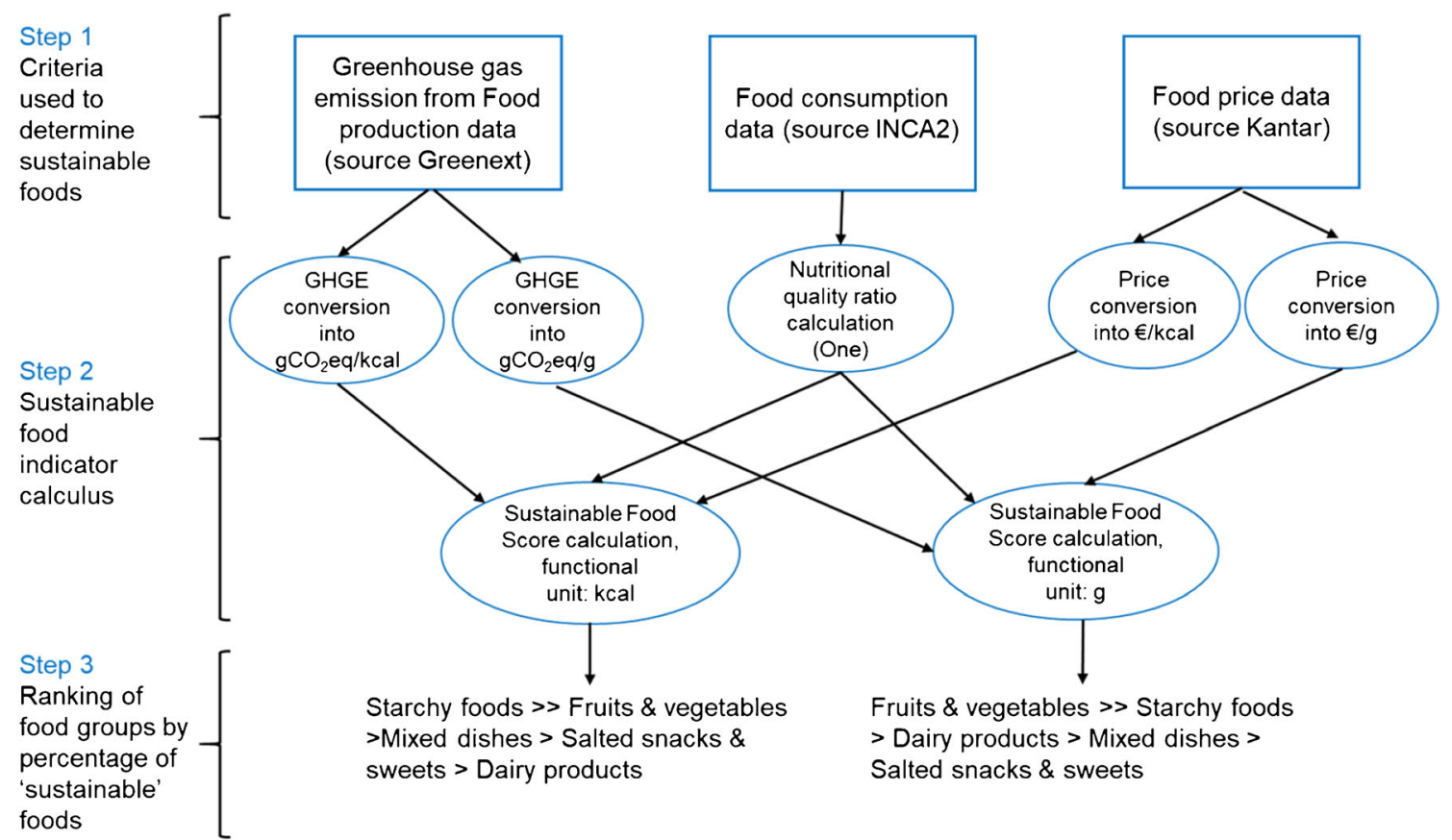

Fig. 4 Illustration representative of studies in cluster 2: design of indicators of sustainable food. This study used data from the French Individual and National Dietary Survey (INCA2), in which individuals recorded food consumption for 1 week. Three sustainability indicators

However, some were also generic, for instance, presenting a method without a dedicated application, such as the method developed by Boukhelifa et al. (2013) to help experts/endusers better explore complex model trade-offs and reach informed decisions (Fig. 6). The main idea behind their development of a prototype visualization tool (EvoGraphDice), which supports Evolutionary Visual Exploration (a combination of visual analysis and interactive evolutionary were chosen: environmental impact (via greenhouse gas emissions (GHGE)), nutritional quality (using two distinct nutrient profiling systems), and price. The dataset included the 402 foods consumed the most in France. Adapted from Masset et al. (2015)

calculation), was that interactive visualization can help users understand trade-offs better (Boukhelifa et al. 2013).

In conclusion, this study clearly highlighted great diversity in the approaches used in the articles selected. A major result is that a large proportion of studies (one-third) used nondedicated methods to analyze a list of indicators. The clustering approach showed a strong influence of scientific disciplines with non-dedicated methods mainly used in animal science (cluster 1) but not (or less frequently) in product

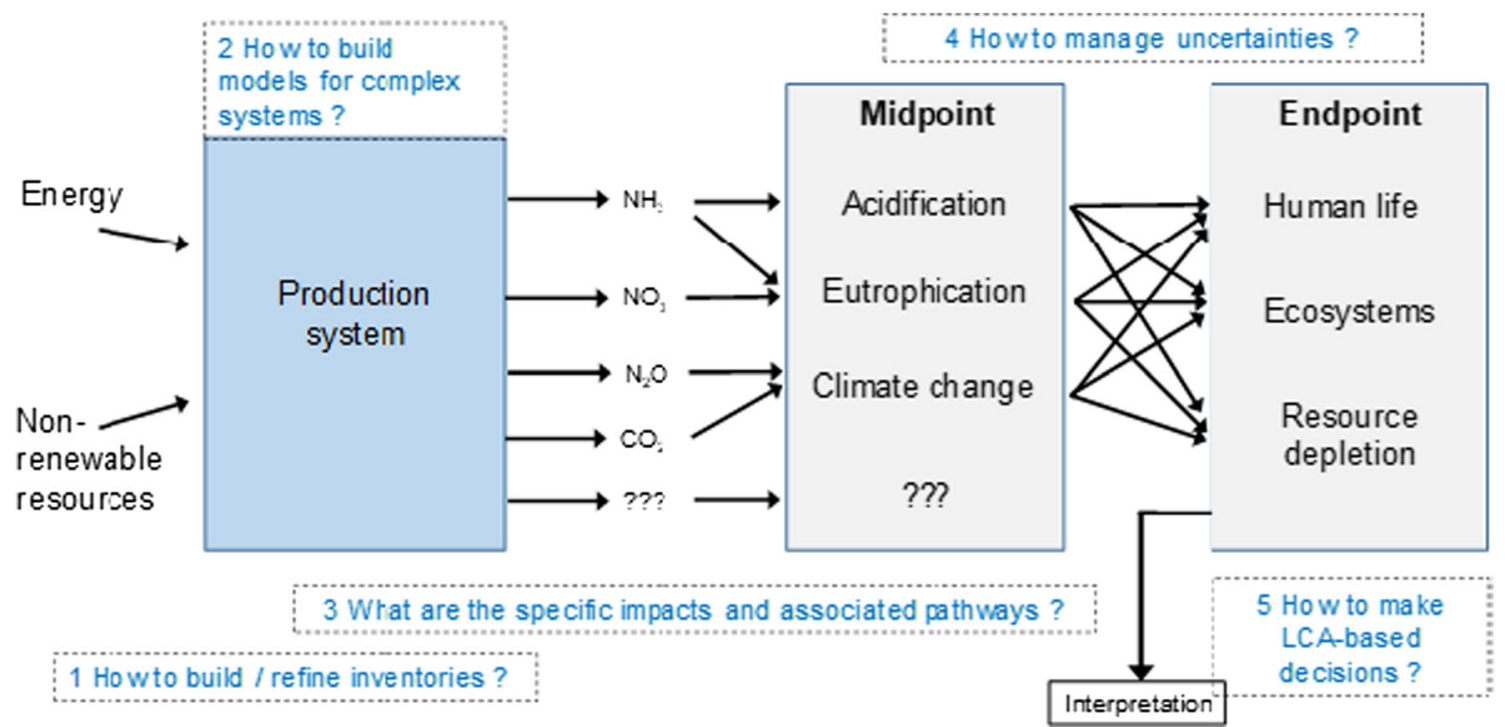

Fig. 5 Illustration representative of studies in cluster 3: scientific issues to consider when applying life cycle assessment (LCA) to the use of waste and biomass. Adapted from Bellon-Maurel et al. (2013) 
Fig. 6 Illustration representative of studies in cluster 4 : development of a generic interactive procedure (Evolutionary Visual Exploration) and tool (EvoGraphDice) to explore multidimensional datasets by combining multiple calculation stages and visual inspection by users. Adapted from Boukhelifa et al. (2013)

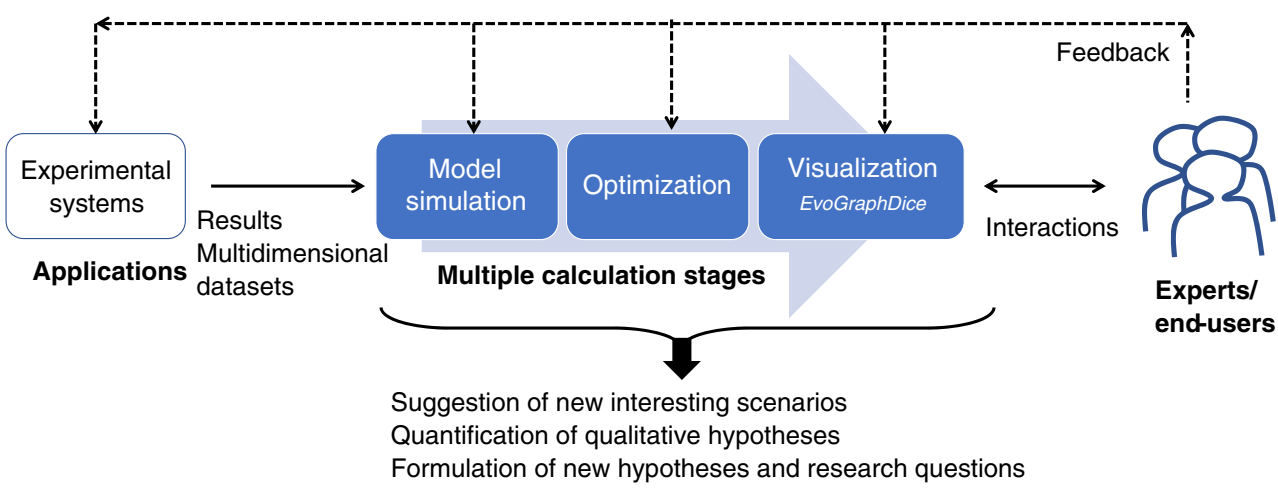

Formulation of new hypotheses and research questions quality and human health disciplines (cluster 2) or in sustainability science (cluster 3). The latter two disciplines use dedicated MCDA methods and focus more on decision support, such as for sorting or selecting the best options. The suggested classification also showed that most articles aim to create knowledge, which can be based on a list of descriptive indicators.

\subsection{Potentiality of MCDA in sustainable agri-food systems}

There is a great potential for improvement of MCDA methods in the agri-food sector, and this study highlighted the potential for applying MCDA methods in research by identifying-via the clusters, which were strongly influenced by disciplinestudies in which MCDA tools, techniques, and concepts can be applied.

The cluster analysis confirmed, via cluster 1 , a relation between "scientists" as the target audience, studies that used a "non-dedicated method," and the purpose "to choose, sort, or rank options." In this case, the lack of a dedicated MCDA method may result in "intuitive," non-transparent aggregation by readers who want to draw conclusions (e.g., about the overall sustainability of a system). As Bockstaller et al. (2017) indicated, non-aggregated indicators and an aggregation procedure are often useful during different stages of an evaluation. MCDA methods are then urgently required to make decisions based on several criteria in order to avoid non-transparent empirical decisions. The relation between product quality and a dedicated method based on optimization (cluster 2) is simple to understand, since optimization is often used in industrial processing, which requires optimal solutions. This raises the question of advantages of other MCDA methods in this sector and highlights the potential for scientists to improve the multi-criteria approach, specifically in the disciplines of animal science (cluster 1), product quality and human health (cluster 2), and sustainability science (cluster 3 ) by using better funded dedicated MCDA methods.

It comes out from the analysis of the MCDA approaches among agri-food research that there are major differences in the dimensions assessed, scales assessed, and stakeholder contributions, which suggest avenues for future research. The environmental and economic dimensions are often addressed, unlike the social dimension. Quality is a major challenge for the agri-food sector, as indicated by its frequency. Many frameworks include product quality in the social (Sadok et al. 2009) or economic dimension (Scialabba et al. 2014). Human health and animal and plant health are less frequent, but the emerging concept of "one health" may encourage studies on these dimensions. Similarly, the FAO's global initiative to consider food safety, nutrition, and economics in decisions may increase use of MCDA in the sector of food safety (FAO 2017). In addition, ecosystem services have rarely been considered in MCDA methods to date, although they are considered in many ecological studies. This relative lack of consideration is expected to change in the coming years.

For spatial scale, most studies focus on the farm scale, while studies at larger scales (e.g., territory, region) are less frequent. Larger-scale studies, such as those of a territory, require datasets that are more difficult to obtain. More interesting is the wide use of static approaches for the temporal scale, which is the common practice in sustainability science. Again, this may be due to the lack of time-series of data. It also results from defining "sustainability" restrictively as the ability to fulfill goals or to satisfy management guidelines. Recently, studies have used concepts such as "viability," "resilience," "robustness," and "vulnerability" (Urruty et al. 2016), which consider dynamic aspects of sustainability. However, these studies did not use a multi-criteria approach and often addressed only criteria such as yield or profitability. Furthermore, ca. $20 \%$ of the studies we reviewed assessed the production cycle, which reflects the use of LCA, which is often used in environmental sciences.

Finally, most studies did not include stakeholders or specify their contributions, but stakeholder involvement is an important issue in sustainability science and operational research. Cluster 4 included only 76 of the 954 articles, perhaps due to their main purpose, which was to create knowledge. Nonetheless, including stakeholders in MCDA studies may increase acceptance and use of the knowledge that the studies 
generate (Macharis and Bernardini 2015; Triste et al. 2014). Many situations can benefit from a participatory approach.

\subsection{Innovative strategy to analyze MCDA approaches in the agri-food sector}

The methodology applied in this study and the results obtained are original and bring several strengths compared to previous reviews of MCDA methods.

This study is the first one to present an overview and analysis of MCDA approaches and methods developed in the agri-food research. To date, no review or meta-analysis has focused specifically on MCDA approaches in the entire agri-food system, taken in its comprehensive span from agriculture production to food consumption including food processing and waste management. Some reviews related to MCDA have been recently published in this sector on water and irrigation (13 reviews), pesticides (3), territories (20), climate change (2), sustainability (17), agricultural production (5), and the farm-to-fork chain (11), but no comprehensive review of the agri-food system exists. The review done in this work addresses a broad range of agrifood fields, including all food products (e.g., meat, fish, fruit and vegetables, cereals, dairy, beverages) and many disciplines (e.g., agronomy, process engineering, environmental sciences, nutrition, mathematics, economics, social sciences) associated with agriculture and food production. Moreover, the review is based on a sample size (954 articles) larger than those of most previous reviews.

Contrary to previous studies, this work proposes an original analytical framework based on eight new criteria derived from preliminary choices in a methodological pathway to assess sustainability (Lairez et al. 2017), such as the purpose ("why?"), audience ("for whom?"), dimension and system/ object assessed ("what?"), spatial scale (“where?"), and temporal scale ("when?"). Existing reviews contain some of these criteria along with other descriptors such as the country, journal, sector, or specific method. For instance, Mardani et al. (2015) used expert opinion to group 393 articles based on 15 criteria and then categorized them further based on authors, publication date, journal name, method, tool, and type of research (MCDA that uses, develops, or proposes research). Certain criteria have not been used in previous reviews. The first criterion - "type of study"-is original and highlights two gradients in MCDA studies: (i) genericity, from application of a MCDA method to generic research on MCDA methodology and (ii) degree of organization and development, from the use of a list of indicators to the development of a generic method. The last criterion- "stakeholder contributions"- also addresses an important issue in the development of MCDA methods. Developing an MCDA method with a participatory approach is considered to increase the success of implementing the method (Triste et al. 2014). The 5-10 subcriteria of the eight criteria we used to describe MCDA methods yielded 58 binary variables, a large number that characterized the diversity of the articles better.

Finally, a major strength of this study was the use of multi-variate and cluster analysis to identify interrelation between criteria. The previous studies showed that MCDA methods have been increasingly used since the 2000s, especially since 2005 , as the concept of sustainable development, which is intrinsically multi-criteria, grew. These reviews mapped the distribution of articles based on criteria such as the period of publication, authors' countries or institutions, and type of journal, but they did not explore whether the criteria were interrelated or/and may help identify clusters in the whole set of publications. Most of them described each criterion individually without analyzing relations among the criteria. Wustenberghs et al. (2015), for instance, calculated correlations between pairs of criteria, thus revealing many associations among them, to examine how sustainability frameworks, metrics, and tools and their use can be improved to future-proof agricultural decisionmaking. Their analysis was not sufficiently developed, however, and they recommended performing cluster analysis to provide decisive conclusions. Some very recent studies successfully developed multi-variate analysis of data as carried out in this study, but not in the agri-food sector. One example is the study of Vörösmarty and Dobos (2020) who reviewed papers on the use of the Data Envelop Analysis (DEA) to select suppliers and run a multivariate analysis and identified several clusters of papers. Cinelli et al. (2020) developed a taxonomy-based approach to classify MCDA to help end-users control the enormous diversity of MCDA methods and to guide them in the selection of the method. Last, Macharis and Bernardini (2015) also went beyond mapping criteria to develop a general framework for evaluating transport projects. It was out of the scope of our review to develop a decision aid like Cinelli et al. (2020) or a methodological framework like Macharis and Bernardini (2015). However, this study carried out a cluster analysis, in the agri-food sector, on much broader sample of methods regarding its size and content than previous authors and was able to identify clusters of methods highlighting diversity and potentialities of MCDA methods.

\section{Conclusion}

This study presents for the first time a comprehensive analysis of a substantial dataset in agri-food research showing the diversity and potentiality of multi-criteria decision analysis methods. It provides bibliometric insights for scientists to use MCDA methods and highlights the richness and diversity of MCDA studies in the agriculture and food sector, including 
many disciplines related to these domains. This study differs from other studies by (i) the sectors covered and their broad definition, (ii) the analytical framework used to define criteria, and (iii) use of multi-variate and cluster analyses.

One major result is the large proportion of studies that used a non-dedicated method based only on a list of indicators, even when the purpose was to choose, sort, or rank options. The clustering approach shows a strong influence of scientific disciplines on the MCDA methods used and the range of their overall degree of use. It highlights potential improvement for disciplines such as animal science, which mainly use non-dedicated methods. For other disciplines, such as those that focus on product quality and human health or sustainability, the issue is whether other MCDA methods are relevant.

Avenues for future agri-food research in which MCDA tools, techniques, and concepts could provide new insights have been identified. For instance, general effort has to be made to focus on including temporal dynamics and changes in spatial scale since studies rarely consider them. Ecosystem services are expected to be included in MCDA methods in the coming years and applied beyond ecological studies. Likewise, participatory science will allow the involvement of stakeholders (i.e., public authorities, governmental agencies) and end-users (i.e., farmers, producers, industrials, consumers) in the construction of the multi-criteria evaluation but also the subsequent decisions. In the future, interdisciplinary exchanges on MCDA methods will likely enable disciplines to better use the potential of these methods. Doing so requires studies that identify the many approaches available and help users apply them.

This study emphasized the added value of MCDA in the entire agri-food sector to move from describing or ranking systems to building evidence-based decisions that consider multiple factors and stakeholders. It was based on a large sample but from one research institute and one country. This stresses the importance of repeating such studies in different contexts, such as at the European scale. Doing so would require including other specific regional criteria to improve the analysis.

Acknowledgments The INRA project EMC-SAGA started in 2016. The authors thank INRA and INRAE for the financial support. In 2020, INRA merged with IRSTEA (National Research Institute of Science and Technology for Environment and Agriculture) to become INRAE, the French National Research Institute for Agriculture, Food and Environment.

\section{Compliance with ethical standards}

Funding This study was funded by INRAE.

Conflict of interest The authors declare that they have no conflict of interest.
Authors' contributions Conceptualization, GGG; methodology, G.G.G., A.A., J.A., C.B., P.B., C.C., A.G., V.M., J-M.M, R.S., M.T-S., and H.v.d.W.; formal analysis, RS, C.B., and M.T-S; investigation, G.G.G., A.A., J.A., C.B., P.B., C.C., A.G., V.M., J-M.M, R.S., M.T-S., and H.v.d.W.; resources, A.G. and P.B.; data curation, G.G.G., A.A., J.A., C.B., P.B., C.C., V.M., J-M.M, R.S., M.T-S., and H.v.d.W.; writing (original draft), G.G.G., A.A., J.A., C.B., R.B., P.B., C.C., A.G., V.M., JM.M, R.S., M.T-S., and H.v.d.W.; writing (review and editing), G.G.G. and R.B.; visualization, G.G.G., J.A., R.B., P.B., C.C., A.G., J-M.M, and H.v.d.W.; supervision and project administration, G.G.G. and R.B.

Data availability Data are available from Gésan-Guiziou et al. (2019).

Ethics approval Not applicable.

Consent to participate Not applicable.

Consent for publication All authors whose names appear on the submission approved the version to be published and agree to be accountable for all aspects of the work in ensuring that questions related to the accuracy or integrity of any part of the work are appropriately investigated and resolved.

Code availability Not applicable.

\section{References}

Ayele D, Zewotir T, Mwambi H (2014) Multiple correspondence analysis as a tool for analysis of large health surveys in African settings. Afr Health Sci 14:1036-1045. https://doi.org/10.4314/ahs.v14i4.35

Bellon-Maurel V, Aissani L, Bessou C, Lardon L, Loiseau E, Risch E, Roux P, Junqua G (2013) What scientific issues in life cycle assessment applied to waste and biomass valorization? Waste Biomass Valoriz 4:377-383. https://doi.org/10.1007/s12649-012-9189-4

Belton V, Stewart TJ (2002) Multiple criteria decision analysis: an integrated approach. Kluwer Academic Publishers, Boston/Dordrecht/ London

Bockstaller C, Beauchet S, Manneville V, Amiaud B, Botreau R (2017) A tool to design fuzzy decision trees for sustainability assessment. Environ Model Softw 97:130-144. https://doi.org/10.1016/j. envsoft.2017.07.011

Boukhelifa N, Cancino W, Bezerianos A, Lutton E (2013) Evolutionary visual exploration: evaluation with expert users. Comput Graph Forum 32:31-40. https://doi.org/10.1111/cgf.12090

Carpani M, Bergez J-E, Monod H (2012) Sensitivity analysis of a hierarchical qualitative model for sustainability assessment of cropping systems. Environ Model Softw 27-28:15-22. https://doi.org/10. 1016/j.envsoft.2011.10.002

Cinelli M, Kadziński M, Gonzalez M, Słowiński R (2020) How to support the application of multiple criteria decision analysis? Let us start with a comprehensive taxonomy. Omega 96:102261. https://doi. org/10.1016/j.omega.2020.102261

Destercke S, Buche P, Charnomordic B (2013) Evaluating data reliability: an evidential answer with application to a web-enabled data warehouse. IEEE Trans Knowl Data Eng 25:92-105. https://doi. org/10.1109/TKDE.2011.179

Destercke S, Buche P, Guillard V (2011) A flexible bipolar querying approach with imprecise data and guaranteed results. Fuzzy Sets Syst 169:51-64. https://doi.org/10.1016/j.fss.2010.12.014

Eakin H, Connors JP, Wharton C, Bertmann F, Xiong A, Stoltzfus J (2017) Identifying attributes of food system sustainability: emerging 
themes and consensus. Agric Hum Values 34:757-773. https://doi. org/10.1007/s10460-016-9754-8

Fagioli FF, Rocchi L, Paolotti L, Słowiński R, Boggia A (2017) From the farm to the agri-food system: a multiple criteria framework to evaluate extended multi-functional value. Ecol Indic 79:91-102. https:// doi.org/10.1016/j.ecolind.2017.04.009

FAO (2017) Food safety risk management: evidence-informed policies and decisions, considering multiple factors. FAO, Rome

Gésan-Guiziou G, Alaphilippe A, Andro M, Aubin J, Bockstaller C, Botreau R, Buche P, Collet C, Darmon N, Delabuis M, Girard A, Grateau R, Kansou K, Martinet V, Membré JM, Sabbadin R, Soler LG, Thiollet-Scholtus M, Tonda A, van-der-Werf H (2019) Annotation data about multi criteria assessment methods used in the agri-food research: The French national institute for agricultural research (INRA) experience. Data Brief 25:104204. https://doi.org/ 10.1016/j.dib.2019.104204

Godfray HCJ, Beddington JR, Crute IR, Haddad L, Lawrence D, Muir JF, Pretty J, Robinson S, Thomas SM, Toulmin C (2010) Food security: the challenge of feeding 9 billion people. Science 327: 812-818. https://doi.org/10.1126/science.1185383

Guillard V, Buche P, Destercke S, Tamani N, Croitoru M, Menut L, Guillaume C, Gontard N (2015) A decision support system to design modified atmosphere packaging for fresh produce based on a bipolar flexible querying approach. Comput Electron Agric 111:131-139. https://doi.org/10.1016/j.compag.2014.12.010

Herva M, Roca E (2013) Review of combined approaches and multicriteria analysis for corporate environmental evaluation. J Clean Prod 39:355-371. https://doi.org/10.1016/j.jclepro.2012.07.058

Le S, Josse J, Husson F (2008) FactoMineR: An R package for multivariate analysis. J Stat Softw 25:1-18. https://doi.org/10.18637/jss. v025.i01

Macharis C, Bernardini A (2015) Reviewing the use of multi-criteria decision analysis for the evaluation of transport projects: time for a multi-actor approach. Transp Policy 37:177-186. https://doi.org/10. 1016/j.tranpol.2014.11.002

Madoumier M, Trystram G, Sébastian P, Collignan A (2019) Towards a holistic approach for multi-objective optimization of food processes: A critical review. Trends Food Sci Technol 86:1-15. https://doi.org/ 10.1016/j.tifs.2019.02.002

Mardani A, Hooker RE, Ozkul S, Yifan S, Nilashi M, Sabzi HZ, Fei GC (2019) Application of decision making and fuzzy sets theory to evaluate the healthcare and medical problems: a review of three decades of research with recent developments. Expert Syst Appl 137:202-231. https://doi.org/10.1016/j.eswa.2019.07.002

Mardani A, Jusoh A, Nor KM et al (2015) Multiple criteria decisionmaking techniques and their applications - a review of the literature from 2000 to 2014. Econ Res-Ekon Istraživanja 28:516-571. https:// doi.org/10.1080/1331677X.2015.1075139

Masset G, Vieux F, Darmon N (2015) Which functional unit to identify sustainable foods? Public Health Nutr 18:2488-2497. https://doi. org/10.1017/S1368980015000579

Meynard J-M, Jeuffroy M-H, Le Bail M et al (2017) Designing coupled innovations for the sustainability transition of agrifood systems.
Agric Syst 157:330-339. https://doi.org/10.1016/j.agsy.2016.08. 002

Nitschelm L, Aubin J, Corson MS, Viaud V, Walter C (2016) Spatial differentiation in life cycle assessment LCA applied to an agricultural territory: current practices and method development. J Clean Prod 112:2472-2484. https://doi.org/10.1016/j.jclepro.2015.09.138

Pope J, Annandale D, Morrison-Saunders A (2004) Conceptualising sustainability assessment. Environ Impact Assess Rev 24:595-616. https://doi.org/10.1016/j.eiar.2004.03.001

Sadok W, Angevin F, Bergez J-É, et al (2008) Ex ante assessment of the sustainability of alternative cropping systems: Implications for using multi-criteria decision-aid methods. A review. Agron Sustain Dev 28:163-174. https://doi.org/10.1051/agro:2007043

Sadok W, Angevin F, Bergez J-E, Bockstaller C, Colomb B, Guichard L, Reau R, Messéan A, Doré T (2009) MASC, a qualitative multiattribute decision model for ex ante assessment of the sustainability of cropping systems. Agron Sustain Dev 29:447-461. https://doi. org/10.1051/agro/2009006

Scialabba N, Food and Agriculture Organization of the United Nations, Food and Agriculture Organization of the United Nations (eds) (2014) SAFA guidelines: sustainability assessment of food and agriculture systems, Version 3.0. Food and Agriculture Organization of the United Nations, Rome

Shumbusho F, Raoul J, Astruc JM, Palhiere I, Lemarié S, FugerayScarbel A, Elsen JM (2016) Economic evaluation of genomic selection in small ruminants: a sheep meat breeding program. Animal 10: 1033-1041. https://doi.org/10.1017/S1751731115002049

Singh RK, Murty HR, Gupta SK, Dikshit AK (2012) An overview of sustainability assessment methodologies. Ecol Indic 15:281-299. https://doi.org/10.1016/j.ecolind.2011.01.007

Triste L, Marchand F, Debruyne L, Meul M, Lauwers L (2014) Reflection on the development process of a sustainability assessment tool: learning from a Flemish case. Ecol Soc 19. https://doi. org/10.5751/ES-06789-190347

Urruty N, Tailliez-Lefebvre D, Huyghe C (2016) Stability, robustness, vulnerability and resilience of agricultural systems. A review. Agron Sustain Dev 36:15. https://doi.org/10.1007/s13593-015-0347-5

Vergara-Solana F, Araneda ME, Ponce-Díaz G (2019) Opportunities for strengthening aquaculture industry through multicriteria decisionmaking. Rev Aquac 11:105-118. https://doi.org/10.1111/raq.12228

Vörösmarty G, Dobos I (2020) A literature review of sustainable supplier evaluation with data envelopment analysis. J Clean Prod 264: 121672. https://doi.org/10.1016/j.jclepro.2020.121672

Wustenberghs H, Coteur I, Debruyne L, Marchand F (2015) Tempag pilot activity 1.1.1: survey of sustainability assessment methods. ILVO. Institut for Agricultural and Fisheries Research, Merelbeke

Zavadskas EK, Antucheviciene J, Vilutiene T, Adeli H (2018) Sustainable decision-making in civil engineering, construction and building technology. Sustainability 10:UNSP 14. https://doi.org/10. 3390/su10010014

Publisher's note Springer Nature remains neutral with regard to jurisdictional claims in published maps and institutional affiliations. 